\title{
TINGKAT KEPUASAN PASIEN TERHADAP PELAYANAN KEFARMASIAN DI PUSKESMAS MADUREJO DAN PUSKESMAS MENDAWAI KECAMATAN ARUT SELATAN KABUPATEN KOTAWARINGIN BARAT
}

\author{
Muhammad Hafizh A.P ${ }^{1}$, Yogie Irawan ${ }^{2}$, Ahmad Irawan ${ }^{3}$ \\ ${ }^{1,2,3}$ STIKES Borneo Cendekia Medika Pangkalan Bun \\ Email: stikesbcm15@gmail.com
}

\begin{abstract}
ABSTRAK
Kepuasan adalah perasaan seseorang yang muncul setelah membandingkan kinerja yang diperkirakan dan kinerja yang diharapkan. Maka dari itu tingkat kepuasan yang diperoleh pelanggan berkaitan pada kualitas jasa yang mereka dapat. Tujuan penelitian untuk mengetahui tingkat kepuasan pasien terhadap pelayanan kefarmasian di Puskesmas Madurejo dan Puskesmas Mendawai Kecamatan Arut Selatan Kabupaten Kotawaringin Barat. Penelitian ini menggunakan desain penelitian bersifat deskriptif, teknik pengambilan sampel teknik purposive sampling. Sampel penelitian sebanyak 186 responden dari Puskesmas Madurejo dan Puskesmas Mendawai. Pengambilan data dilakukan melalui pengisian kuesioner yang telah di uji validitas dan realibilitasnya serta waktu tunggu yang dilakukan dengan menggunakan stopwatch. Hasil penelitian menunjukan bahwa tingkat kepuasan persentase rata rata secara keseluruhan sebesar $(94,90 \%)$ pada Puskesmas Madurejo dan $(95,63)$ Pada Puskesmas Mendawai dengan kategori kepuasan adalah sangat puas. Hasil penelitian tentang waktu tunggu pelayanan resep memiliki rata - rata waktu tunggu resep racikan 10 menit pada kedua Puskesmas, sedangkan waktu tunggu resep obat non racikan adalah 3 menit Puskesmas Madurejo dan 5 Menit Puskesmas Mendawai. berdasarkan hasil penelitian diperoleh bahwa tingkat kepuasan pasien terhadap pelayanan kefarmasian di Puskesmas Madurejo dan Puskesmas Mendawai dalam kategori sangat puas.
\end{abstract}

Kata Kunci: Tingkat kepuasan, Waktu Tunggu, Kefarmasian, Deskriptif.

\begin{abstract}
Satisfaction is a person's feelings that arise after comparing the expected performance and the expected performance. Therefore, the level of satisfaction obtained by customers is related to the quality of service they get. The research objective was to determine the level of patient satisfaction with pharmaceutical services at Madurejo and Mendawai Public Health Center Arut Selatan Kotawaringin Barat District. This study used descriptive research design, the sampling technique was purposive sampling. The research sample was 186 respondents from Madurejo
\end{abstract}


and Mendawai Public Health Care. The data was collected by filling out a questionnaire that had been tested for its validity and reliability as well as the waiting time which was carried out using a stopwatch. The results showed that the overall average percentage level of satisfaction was (94.90\%) at Madurejo and (95.63) at Mendawai Public Health Center with the satisfaction category was very satisfied. The results of the study on the waiting time for prescription services had an average waiting time for prescription concoctions of 10 minutes at both, while the waiting time for prescription non-concocted drugs was 3 minutes at Madurejo and 5 minutes at Mendawai Public Health Center. Based on the results of the study, it was found that the level of patient satisfaction with pharmaceutical services at Madurejo and Mendawai Public Health Center was in the very satisfied category.

Keywords: Satisfaction Level, Waiting Time, Pharmacy, Descriptive.

\section{PENDAHULUAN}

Standar kepuasan pasien di pelayanan kesehatan ditetapkan secara nasional oleh Departemen Kesehatan. Menurut Peraturan Kementrian Kesehatan Republik Indonesia Tahun 2016 tentang Standar Pelayanan Minimal untuk kepuasan pasien pada pelayanan kesehatan yaitu diatas 95\% (Kemenkes, 2016). Melihat Bagaimana tingkat kepuasaan pasien terhadap pelayanan kefarmasian bedasarkan dimensi Service Quality serta gambaran waktu tunggu pelayanan kefarmasian di Puskesmas Madurejo dan Puskesmas Mendawai Kecamatan Arut Selatan. Bertujuan mengetahui tingkat kepuasan pasien berdasarkan dimensi Service Quality serta sesuai resep (Yuliani dan Victoria, 2019).

\section{METODE PENELITIAN}

Data Penelitian ini diperoleh
dari Puskesmas Madurejo dan
Puskesmas Mendawai Arut Selatan
Kotawaringin Barat berdasarkan
kriteria tertentu yang digunakan
diambil menggunakan teknik

gambaran waktu tunggu Puskesmas Madurejo dan Puskesmas Mendawai.

Kepuasan adalah perasaan senang atau kecewa seseorang yang muncul setelah membandingkan anatara kinerja (hasil) produk yang diperkirakan terhadap kinerja yang diharapkan. Jika kinerja dibawah harapan, konsumen tidak puas. Jika kinerja memenuhi harapan, konsumen puas. Jika kinerja melebihi harapan, konsumen sangat puas (Kotler, 2016). Waktu tunggu pelayanan resep adalah total waktu pelayanan resep obat di layanan kesehatan seperti puskesmas mencakup dari pasien memberikan resep pada apotek, skrining resep, penyiapan obat, peracikan obat, pemberian etiket sampai dengan petugas apotek menyerahkan obat

purposive sampling, pengumpulan data tingkat kepuasan menggunakan kuesioner dan waktu tunggu pelayanan resep menggunakan stopwatch, Data yang dikumpulkan kemudian dibuat dalam bentuk tabulasi dan dianalisis menggunakan rumus persentase serta 
analisis data waktu tunggu menggunakan persentase rata- rata pelayanan resep untuk melihat perbedaan waktu tunggu antara obat jadi dan obat racik serta melihat waktu perbedaan anatara dua Puskesmas.

\section{HASIL DAN PEMBAHASAN}

Data penelitian ini diperoleh secara keseluruhan 186 responden dari Puskesmas Madurejo dan Puskesmas
Mendawai. Penelitian ini mengkaji tanggapan responden terhadap kepuasan pasien mengacu pada lima dimensi Service Quality, secara umum dapat dilihat dari hasil penelitian mengenai tingkat kepuasan pasien di Puskesmas Madurejo dan Puskesmas Mendawai Kecamatan Arut Selatan Kabupaten Kotawaringin Barat, responden menunjukan kepuasannya pada pelayanan kefarmasian.

Tabel 1. Dimensi Kehandalan (Reliability)

\begin{tabular}{|c|c|c|c|c|c|c|}
\hline \multirow[b]{2}{*}{ No } & \multirow{2}{*}{ Jenis Pertanyaan } & \multicolumn{2}{|c|}{ Madurejo } & \multicolumn{2}{|c|}{ Mendawai } & \multirow{2}{*}{ Kriteria } \\
\hline & & $\mathbf{n}$ & $\%$ & $\mathbf{N}$ & $\%$ & \\
\hline 1 & Kecepatan Pelayanan Obat & 439 & 93,40 & 421 & 91,52 & Sangat Puas \\
\hline 2 & Obat tersedia dengan lengkap & 425 & 90,43 & 424 & 92,17 & Sangat Puas \\
\hline 3 & $\begin{array}{l}\text { Petugas Apotek melayani dengan ramah dan } \\
\text { tersenyum }\end{array}$ & 428 & 91,06 & 425 & 92,39 & Sangat Puas \\
\hline \multirow[t]{2}{*}{4} & Petugas selalu siap membantu & 433 & 92,13 & 439 & 95,43 & Sangat Puas \\
\hline & Rata - Rata & 431 & 91,76 & 427,3 & 92,88 & Sangat Puas \\
\hline \multicolumn{7}{|c|}{ Sumber: Data Primer } \\
\hline \multicolumn{2}{|c|}{$\begin{array}{l}\text { Berdasarkan tabel } 1 \text {. terlihat } \\
\text { bahwa rata- rata persentase terkait } \\
\text { tingkat kepuasan pasien berdasarkan } \\
\text { dimensi reliability adalah }(91,76 \%) \\
\text { pada Puskesmas Madurejo dengan } 94 \\
\text { responden dan (92,88\%) pada } \\
\text { Puskesmas Mendawai dengan } 92 \\
\text { responden. Hasil dari jawaban } \\
\text { responden sesuai dengan pelayanan }\end{array}$} & \multicolumn{5}{|c|}{$\begin{array}{l}\text { yang diberikan terhadap responden } \\
\text { berdasarkan kecepatan pelayanan obat, } \\
\text { ketersediaan obat dan petugas } \\
\text { memberikan pelayanan yang ramah } \\
\text { kepada pasien termasuk dalam } \\
\text { kategori sangat puas di Puskesmas } \\
\text { Madurejo dan Puskesmas Mendawai. }\end{array}$} \\
\hline \multicolumn{7}{|c|}{ Tabel 2. Dimensi Ketanggapan (responsiveness) Puskesmas Madurejo dan Puskesmas Mendawai } \\
\hline \multirow{2}{*}{ No } & \multirow{2}{*}{ Jenis Pertanyaan } & \multicolumn{2}{|c|}{ Madurejo } & \multicolumn{2}{|c|}{ Mendawai } & \multirow{2}{*}{ Kriteria } \\
\hline & & n & & $\mathbf{n}$ & $\%$ & \\
\hline 1 & $\begin{array}{l}\text { Petugas Apotek cepat tanggap terhadap } \\
\text { keluhan pasien }\end{array}$ & 44 & 93,8 & 445 & 96,74 & Sangat Puas \\
\hline 2 & $\begin{array}{l}\text { Petugas Apotek mampu memberikan } \\
\text { penyelesaian masalah yang dihadapi pasien }\end{array}$ & 45 & 95, & 445 & 96,74 & Sangat Puas \\
\hline
\end{tabular}


3 Terjadi komunikasi yang baik antara petugas Apotek dengan pasien

4 Pasien mendapatkan informasi yang jelas dan mudah dimengerti tentang resep/obat yang ditebusnya

Rata - Rata

Sumber: Data Primer

Berdasarkan tabel 2. terlihat bahwa rata- rata persentase terkait tingkat kepuasan pasien berdasarkan dimensi Responsiveness adalah (95,69\%) pada Puskesmas Madurejo dengan 94 responden dan $(97,17 \%)$
$454 \quad 96,60 \quad 447 \quad 97,17 \quad$ Sangat Puas

$\begin{array}{lllll}453 & 96,38 & 451 & 98,04 & \text { Sangat Puas }\end{array}$

$\begin{array}{lllll}449,8 & 95,69 & 447 & 97,17 & \text { Sangat Puas }\end{array}$

pada Puskesmas Mendawai dengan 92 responden. Dapat diambil kesimpulan pelayanan kefarmasian di Puskemas Madurejo dan Puskesmas Mendawai berdasarkan dimensi Responsiveness dari persepsi pasien adalah sangat memuaskan.

Tabel 3. Dimensi Jaminan (Assurance) Puskesmas Madurejo dan Puskesmas Mendawai

\begin{tabular}{|c|c|c|c|c|c|c|}
\hline \multirow{2}{*}{ No } & \multirow{2}{*}{ Jenis Pertanyaan } & \multicolumn{2}{|c|}{ Madurejo } & \multicolumn{2}{|c|}{ Mendawai } & \multirow{2}{*}{ Kriteria } \\
\hline & & $\mathbf{n}$ & $\%$ & $\mathbf{n}$ & $\%$ & \\
\hline 1 & $\begin{array}{l}\text { Petugas Apotek mempunyai pengetahuan dan } \\
\text { keterampilan yang baik dalam bekerja }\end{array}$ & 441 & 93,83 & 455 & 98,91 & Sangat Puas \\
\hline 2 & Obat yang diperoleh terjamin kualitasnya & 439 & 93,40 & 444 & 96,52 & Sangat Puas \\
\hline \multirow[t]{2}{*}{3} & $\begin{array}{l}\text { Obat yang diberikan sesuai dengan yang } \\
\text { diminta }\end{array}$ & 450 & 95,74 & 442 & 96,09 & Sangat Puas \\
\hline & Rata - Rata & 443,3 & 94,33 & 447 & 97,17 & Sangat Puas \\
\hline \multicolumn{7}{|c|}{ Sumber: Data Primer } \\
\hline \multicolumn{2}{|c|}{$\begin{array}{l}\text { Berdasarkan tabel 3. terlihat } \\
\text { bahwa rata- rata persentase terkait } \\
\text { tingkat kepuasan pasien berdasarkan } \\
\text { dimensi Assurance adalah }(94,33 \%) \\
\text { pada Puskesmas Madurejo dengan } 94 \\
\text { responden dan (97,17\%) pada } \\
\text { Puskesmas Mendawai dengan } 92\end{array}$} & \multicolumn{5}{|c|}{$\begin{array}{l}\text { responden. Dapat disimpulkan bahwa } \\
\text { Puskesmas Madurejo dan Puskesmas } \\
\text { Mendawai memberikan pelayanan } \\
\text { dimensi jaminan yang sangat } \\
\text { memuaskan kepada pasien. }\end{array}$} \\
\hline \multirow{2}{*}{ No } & \multirow{2}{*}{ Jenis Pertanyaan } & \multicolumn{2}{|c|}{ Madurejo } & \multicolumn{2}{|c|}{ Mendawai } & \\
\hline & & $\mathbf{n}$ & $\%$ & $\mathbf{n}$ & $\%$ & Kriteria \\
\hline 1 & $\begin{array}{l}\text { Petugas Apotek memberikan perhatian terhadap } \\
\text { keluhan pasien }\end{array}$ & 456 & 97,02 & 450 & 97,83 & Sangat Puas \\
\hline 2 & $\begin{array}{l}\text { Petugas Apotek memberikan pelayanan kepada } \\
\text { semua pasien tanpa memandang status social }\end{array}$ & 454 & 96,60 & 452 & 98,26 & Sangat Puas \\
\hline
\end{tabular}


3 Petugas menggunakan bahasa yang mudah dimengerti oleh pasien pada saat berkomunikasi

$452 \quad 96,17 \quad 445 \quad 96,74 \quad$ Sangat Puas

Rata - Rata

$\begin{array}{lllll}454 & 96,61 & 449 & 97,61 & \text { Sangat Puas }\end{array}$

Sumber: Data Primer

Berdasarkan tabel 4. terlihat bahwa rata- rata persentase terkait tingkat kepuasan pasien berdasarkan dimensi Emphaty adalah (96,61\%) pada Puskesmas Madurejo dengan 94 responden dan $(97,61 \%)$ pada

Puskesmas Mendawai dengan 92 responden. Dapat diambil kesimpulan bahwa pelayanan kefarmasian di Puskesmas Madurejo dan Puskesmas Mendawai berdasarkan dimensi empati masuk kedalam kategori sangat puas.

Tabel 5. Dimensi Bukti Langsung (Tangible) Puskesmas Madurejo

\begin{tabular}{|c|c|c|c|c|c|c|c|}
\hline \multirow{2}{*}{ No } & \multirow{2}{*}{ Jenis Pertanyaan } & \multicolumn{2}{|c|}{ Madurejo } & \multicolumn{2}{|c|}{ Mendawai } & \multirow{2}{*}{$\begin{array}{c}\text { Kriteria } \\
\text { Madurejo }\end{array}$} & \multirow{2}{*}{$\begin{array}{l}\text { Kriteria } \\
\text { Mendawai }\end{array}$} \\
\hline & & $\mathbf{n}$ & $\%$ & $\mathbf{n}$ & $\%$ & & \\
\hline 1 & $\begin{array}{l}\text { Apotek terlihat bersih dan } \\
\text { rapi }\end{array}$ & 410 & 87,23 & 422 & 91,74 & $\begin{array}{l}\text { Sangat } \\
\text { Puas }\end{array}$ & $\begin{array}{l}\text { Sangat } \\
\text { Puas }\end{array}$ \\
\hline 2 & $\begin{array}{l}\text { Kenyamanan ruang } \\
\text { tunggu }\end{array}$ & 382 & 81,28 & 421 & 91,52 & Puas & $\begin{array}{l}\text { Sangat } \\
\text { Puas }\end{array}$ \\
\hline 3 & $\begin{array}{l}\text { Penataan eksterior dan } \\
\text { interior ruangan }\end{array}$ & 407 & 86,6 & 425 & 92,39 & $\begin{array}{l}\text { Sangat } \\
\text { Puas }\end{array}$ & $\begin{array}{l}\text { Sangat } \\
\text { Puas }\end{array}$ \\
\hline 4 & $\begin{array}{l}\text { Petugas Apotek } \\
\text { berpakaian bersih dan rapi }\end{array}$ & 452 & 96,17 & 449 & 97,61 & $\begin{array}{l}\text { Sangat } \\
\text { Puas }\end{array}$ & $\begin{array}{l}\text { Sangat } \\
\text { Puas }\end{array}$ \\
\hline & Rata - Rata & 412,8 & 87,82 & 429 & 93,32 & $\begin{array}{l}\text { Sangat } \\
\text { Puas }\end{array}$ & $\begin{array}{l}\text { Sangat } \\
\text { Puas }\end{array}$ \\
\hline
\end{tabular}

Sumber: Data Primer

Berdasarkan tabel 5. terlihat bahwa rata- rata persentase terkait tingkat kepuasan pasien berdasarkan dimensi Tangible adalah $(87,82 \%)$ pada Puskesmas Madurejo dengan 94 responden dan $(93,32 \%)$ pada Puskesmas Mendawai dengan 92

\section{Waktu Tunggu Pelayanan Resep}

Dari hasil pengumpulan data diperoleh jumlah sebanyak 186 resep yang terdiri dari obat jadi dan resep obat racik. responden. Kedua Puskesmas yaitu Puskesmas Madurejo dan Puskesmas Mendawai nilai persentase menunjukan responden merasakan pelayanan kefarmasian di puskesmas sangat memuaskan.

Dari 186 resep, Obat non racikan berjumlah $94,1 \%(175$ resep), sedangkan obat racik berjumlah $5,9 \%$ (11 resep).

Tabel 6. Rata - rata Waktu Tunggu Pelayanan Resep Puskesmas Mendawai Bulan Maret April 2020

\begin{tabular}{lccccc}
\hline \multirow{2}{*}{ Puskesmas } & Jenis Resep & $\begin{array}{c}\text { Jumlah } \\
\text { Resep }\end{array}$ & \begin{tabular}{c} 
Jumlah \\
Waktu \\
\cline { 4 - 5 }
\end{tabular} & & \multicolumn{2}{c}{$\begin{array}{c}\text { Rata }- \text { Rata Waktu Tunggu } \\
\text { Tunggu }\end{array}$} & (Mari Hasil & Standar \\
\hline
\end{tabular}




\begin{tabular}{cccccc}
\cline { 4 - 5 } & & (Menit) & Penelitian & $\begin{array}{c}\text { Pelayanan } \\
\text { Minimal }\end{array}$ \\
\hline \multirow{2}{*}{ Madurejo } & Racikan & 7 & & & $\leq 60$ Menit \\
\cline { 2 - 6 } & Non Racikan & 87 & 259,2 & 3 & $\leq 30$ Menit \\
\hline \multirow{2}{*}{ Mendawai } & Racikan & 4 & 43 & 10 & $\leq 60$ Menit \\
\cline { 2 - 6 } & Non Racikan & 88 & 483 & 5 & $\leq 30$ Menit \\
\hline
\end{tabular}

Sumber: Data Primer

Berdasarkan tabel 5.17 Apabila dilihat dari standar pelayanan minimal untuk rata - rata obat Non racikan dan obat racikan yang dalam Kepmenkes No 129/Menkes/SK/II/2008 tentang Standar Pelayanan Minimal yaitu untuk resep racikan $\leq 60$ Menit dan resep obat non racikan $\leq 30$ Menit. Analisis selanjutnya adalah membandingkan waktu tunggu obat racikan dan non racikan antara 2 Puskesmas. Terdapat perbedaan waktu tunggu pelayanan resep untuk obat jadi di Puskesmas Madurejo dan Puskesmas Mendawai. Waktu tunggu pelayanan resep obat non racikan di Pusekesmas Madurejo memiliki ratarata pengerjaan selama 3 menit dan

\section{KESIMPULAN DAN SARAN}

Berdasarkan hasil penelitian dapat disimpulkan bahwa dari 94 responden pada Puskesmas Madurejo dan 92 responden pada Puskesmas Mendawai persentase tertinggi yang didapat setiap Puskesmas adalah dimensi Emphaty dengan nilai $(98,72 \%)$ pada Puskesmas Madurejo dan $(97,61)$ pada Puskesmas Mendawai.
Puskesmas Mendawai memiliki rata rata pengerjaan resep 5 menit. Untuk pengerjaan obat racikan di kedua Puseksmas memiliki rata - rata waktu pengerjaan yang sama yaitu 10 menit.

Banyak faktor yang dapat mempengaruhi waktu tunggu pelayanan resep. Faktor pertama adalah jumlah petugas pelayanan kefarmasian di Puskesmas. Faktor Kedua, Jumlah obat yang diracik pada obat racikan serta banyak tidaknya resep yang masuk mempengaruhi waktu tunggu pelayanan resep. Ketiga adalah sarana dan prasarana termasuk penggunaan teknologi komputer dalam pelayanan resep.

Nilai terendah pada Puskesmas Madurejo terdapat pada dimensi Bukti Langsung (Tangible) dengan nilai $(89,79 \%)$ dan nilai terendah pada Puskesmas Mendawai adalah dimensi Kehandalan(Reliability) dengan nilai $(92,88 \%)$. Persentase terendah pada kedua puskesmas ini diatas $85 \%$ yang artinya tingkat kepuasan pasien tersebut sangat puas. 
DAFTAR PUSTAKA

Kotler, Philip and Kevin Lane Keller, 2016. Marketing Managemen, 15 th Pearson Education, inc,

Kementrian Kesehatan RI

Badan Litbangkes. 2016. Memelihara

Kesehatan Kehamilan : Jakarta
Yuliani Ni Nyoman, Letde Victoria. 2018. Analisis Waktu Tunggu Pelayanan Resep di Puskesmas Pasir Panjang Kota Kupang Bulan April Tahun 2018 : Jurnal Inovasi Kebijakan. 